\title{
Investigation of the structure and properties of nanoscale TiNiNb compositions obtained by high-energy exposure
}

\author{
Peter Rusinov ${ }^{1 a}$, Zhesfina Blednova $^{1}$ \\ ${ }^{1}$ Department "Dynamics and strength of machines", Kuban State Technological University,350072 Moskovskaya 2, Krasnodar, \\ Russian Federation
}

\begin{abstract}
The article describes a complex method of surface modification of steel materials with shape memory effect (SME) TiNiNb, using high-speed gas-flame spraying of mechanically activated powder in a protective environment. We defined the control parameters of the surface modification which monitor the structural state of the material, and allow effecting purposefully on the functional properties of the surface layer with SME. We also developed a statistical model of technological process, which allows optimizing the structurally sensitive mechanical properties and ensuring the formation of nanocrystalline structure. Basing on the phase composition analysis and the average grain size we defined correlation of properties of the coatings to their structural-phase state. X-ray studies have shown that the formation of the surface layers using the developed technology ensures the shape memory effect. We demonstrated the effect that the structural state of surface-modified layer has on microhardness and wear resistance.
\end{abstract}

\section{Introduction}

Characteristics of structure and properties of alloys with shape memory effect (SME) based on TiNi is being intensely studied $[1,2]$. This is, above all, because of their great ability to reversible forming (recovery of inelastic deformations is up to $10 \%$ ), besides the well-known high rates of physical and mechanical properties such as corrosion resistance, wear resistance, vibration damping [3]. For wider use in technology we must have a TiNi based alloys with different temperature intervals of martensitic transformation and hysteresis range. Titanium nickelide alloying is an efficient way to affect the physical and mechanical properties, temperature, hysteresis, martensitic transformation and therefore - the whole complex of functional properties. Thus, for alloys with shape memory effect working in low temperatures (cryogenics) TiNi alloying with the third alloying element such as $\mathrm{Nb}$ is used. One of the most important advantages of TiNiNb alloys, unlike $\mathrm{TiNi}$, is the low temperature range of martensitic transformations while maintaining high reactive stress $\left(\sigma_{\mathrm{r}}{ }^{\max } \approx 500 \mathrm{MPa}\right)$. In alloys with SME the TiNiNb martensitic transformations take place according to the sceme $\mathrm{B} 2 \rightarrow \mathrm{B} 19^{\prime}$ when cooled, and reverse transformation $\mathrm{B} 19^{\prime} \rightarrow \mathrm{B} 2$ when heated [4]. This distinguished TiNiNb alloys from other low temperature alloys based on $\mathrm{TiNi}$, which have intermediate $\mathrm{R}$ phases [3]. During the martensitic transformation soft particles of niobium perceive mechanical impact from the growing martensite crystals and, being plastically deformed under this effect, provide relaxation of the martensite elastic energy, which leads to its further stabilization [5]. It is known that SME alloy $\mathrm{TiNiNb}$ is used as thermomechanical unions for piping connections. The accomplished tests $[6,7]$ confirmed the airtightness and reliability of the compounds in the temperature range from room temperature to $300{ }^{\circ} \mathrm{C}$, as well as easy disassembly of pipelines in deep freezing [7]. Alloys with SME as a functional ones have unique application [2], but their high cost limits the use in mechanical engineering. Efficiency and costeffectiveness of using alloys with shape memory effect in various branches of mechanical engineering can be achieved both by alloying the third component, and by forming of multi-functional composite surface layers with multicomponent materials with shape memory effect [810]. One such variant of composition, "Steel - layer with SME based on TiNiNb», formed by high-speed gas-flame spraying of mechanically activated powder PN46T38NB16 is considered in this study.

The aim of this work is to develop technologies of forming composition "Steel - layer with SME based on TiNiNb» with high-speed gas-flame spraying of mechanically activated powder for functional and mechanical properties, and create a cost-effective functional materials and components on this basis.

\section{The technology of forming TiNiNb composite surface layer}

\footnotetext{
a Corresponding author: ruspiter5@mail.ru
} 
Formation of surface layers was made by high-speed gasflame spraying of mechanically activated powder by means of materials with SME based on PN46T38NB16 using the modernized apparatus GLC-720. The chemical composition of the powder PN46T39NB16 presented in Table 1.

Table 1. Chemical composition of the powder PN46T39NB16,

\begin{tabular}{|c|c|c|c|c|c|c|c|}
\hline PN46T39NB16 & Ni & Ti & Nb & $\mathbf{C}$ & $\mathbf{C a}$ & $\mathbf{N}$ & $\mathbf{H}$ \\
\cline { 2 - 8 } & 46,02 & 37,62 & 16,07 & 0,06 & 0,10 & 0,06 & 0,07 \\
\hline
\end{tabular}

Coating was carried out in argon environment on steel 321. For mechanical activation and grinding of the powder PN46T38NB16 we used a ball mill Hephaestus 2 (AGO-2U) with the following parameters: speed of the drum - $1200 \mathrm{~min}^{-1}$, the carrier speed $-900 \mathrm{~min}^{-1}$, the diameter of steel balls $-6 \mathrm{~mm}$, operating time $-10-30$ min. For coating we used mechanically activated powder PN46T38NB16, which was mainly in the B2-phase ( $70 \%$ ) (Figure 1, a, b).

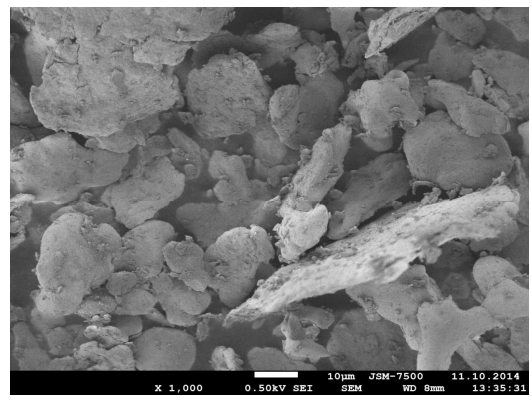

a)

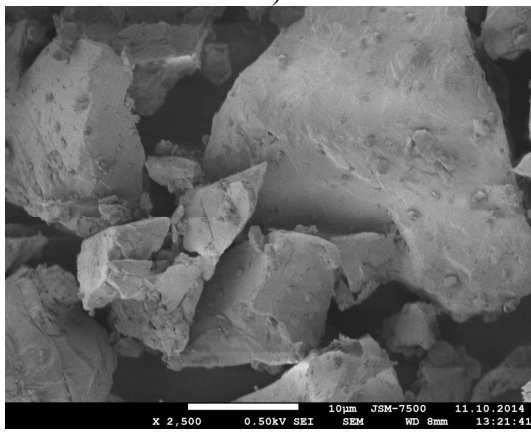

b)
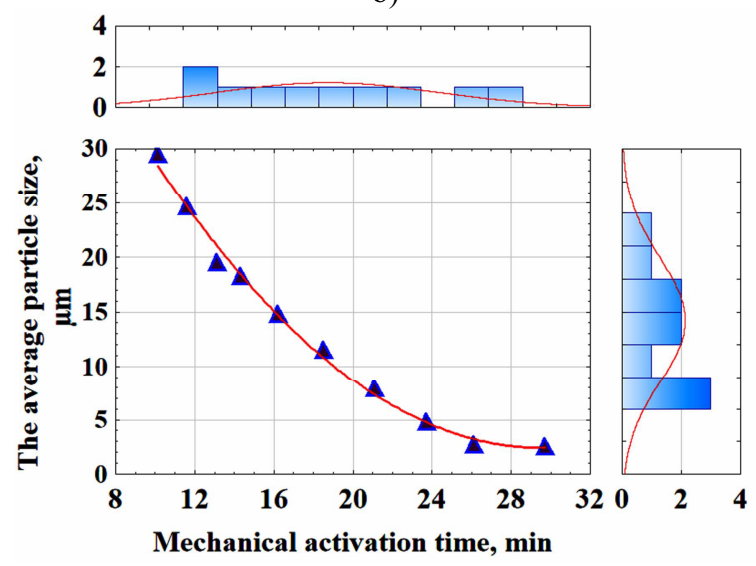

c)

Figure 1. Powder PN46T38NB16 was ground and mechanically activated in attritor GEFEST-2 for 20 minutes: a) $\times 1000$; b) $\times 2500$; the time effect of mechanical activation on the particle size of the powder PN46T38NB16: c).
Dependence of the average particle size of the powder from the activation time is described by equation (1) obtained by experimental data processing in the program Statistica 10.0.

$\mathrm{D}=62,7252-4,085 \cdot \mathrm{T}+0,0692 \cdot \mathrm{T}^{2}$

where $\mathrm{T}$ is the time of mechanical activation, min;

D - average particle size of the powder.

To improve the adhesion strength of the TiNiNb coating with the substrate it was exposed to cleaning and shot peening. Then mechanically activated nickel powder (PNA 1) was sprayed. This created the intermediate sublayer Ni with thickness of 80 microns. Ni sublayer is necessary as a binder between the steel 321 matrix and the TiNiNb coating. The thickness of the modified TiNiNb layer is $0.5 \mathrm{~mm}$ and it has three specific areas: a uniform TiNiNb layer, transition layer $(\sim 80 \mu \mathrm{m})$ and the base metal. Due to the nature and characteristics of highspeed gas-flame spraying in protective environment (argon), during application of $\mathrm{TiNiNb}$ in the surface layer a nano-crystalline structure is formed. The main process parameters of high-speed gas-flame spraying include: Methane flow rate in the range of $60-901 / \mathrm{min}$, oxygen $130-180 \mathrm{l} / \mathrm{min}$, the flow rate of the powder and carrier gas (argon), the distance and angle of spraying, and the feed speed of the torch, rotation speed of the coated part (Figure 2). These parameters define such characteristics as the coating adhesion to the substrate, the cohesive strength, the level of residual stress, porosity, structure and thickness of the sprayed layer.

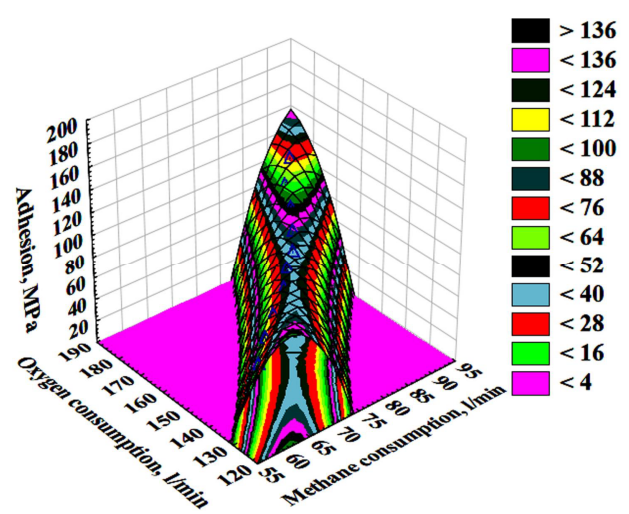

a)

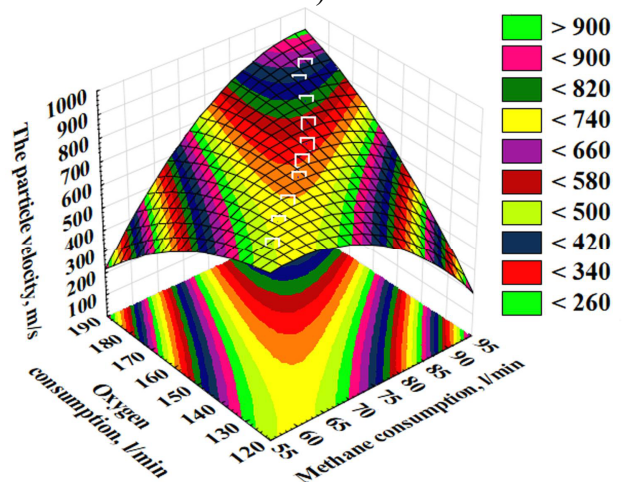

b)

Figure 2. Effect of the combustible gases composition on the adhesive strength of the TiNiNb coating to the substrate - a); on the speed of powder particles - $b$ ). 
Correlation of coating adhesion strength to the substrate and the speed of the powder particles to the technological parameters of the spraying process (oxygen consumption, methane consumption), is described by equations $(2,3)$. They were obtained by experimental data analysis in the program Statistica 10.0.

$\sigma_{\mathrm{adh}}=692,3-1,94 \cdot \mathrm{M}-7,46 \cdot \mathrm{K}-0,602 \cdot \mathrm{M}^{2}+0,629 \cdot \mathrm{M} \cdot \mathrm{K}-$ $0,135 \cdot K^{2}$

$\mathrm{V}=1284,1-0,9275 \cdot \mathrm{M}-8,7807 \cdot \mathrm{K}-0,4266 \cdot \mathrm{M}^{2}+$ $0,4326 \cdot \mathrm{M} \cdot \mathrm{K}-0,0714 \cdot \mathrm{K}^{2}$

where $\mathrm{M}$ is methane consumption, $1 / \mathrm{min}$;

$\mathrm{K}$ is oxygen consumption, $1 / \mathrm{min}$.

Macro and microanalysis of TiNiNb surface layers, received on mastered technology, has shown that the coating structure is rather dense. The interface between the coating and the substrate material has no visible defects (Figure 3a). When powder particles pass through the gas-flame jet they heat up and after striking the substrate they solidify in shape of deformed disks with diameter 15-30 $\mu \mathrm{m}$, thickness 3-15 microns. The grain size in the coating obtained by gas-flame spraying in high protective environment (argon) is $60 \div 97 \mathrm{~nm}$ (Figure $3 \mathrm{~b}$ - with Figure 4a).

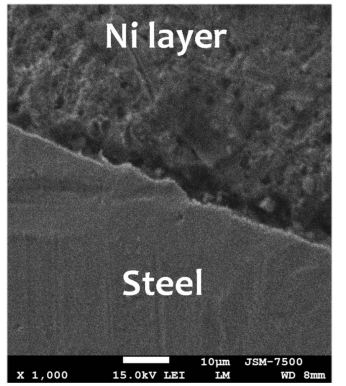

a)

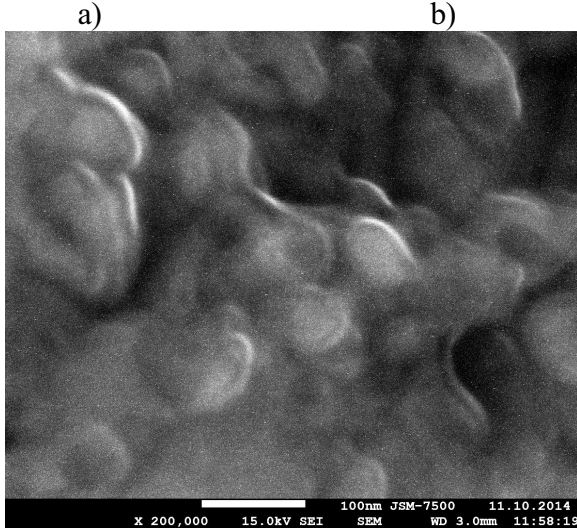

c)

Figure 3. Microstructure under layer Ni - steel 321: a) $-\times 1000$; $\mathrm{TiNiNb}$ coating microstructure obtained by high-speed gasflame spraying: b) $-\times 5000$; c) $-\times 200000$.

Microhardness of TiNiNb layer ranges $\mathrm{H}_{\mu}=8,2 \div 10,5$ GPa (Figure 4, b). Such microhardness increase can be explained by the fact that due to the high collision velocity between particles and substrate, high rate of their cooling and rapid alloy quenching, the high strength metastable nanostructures are formed.

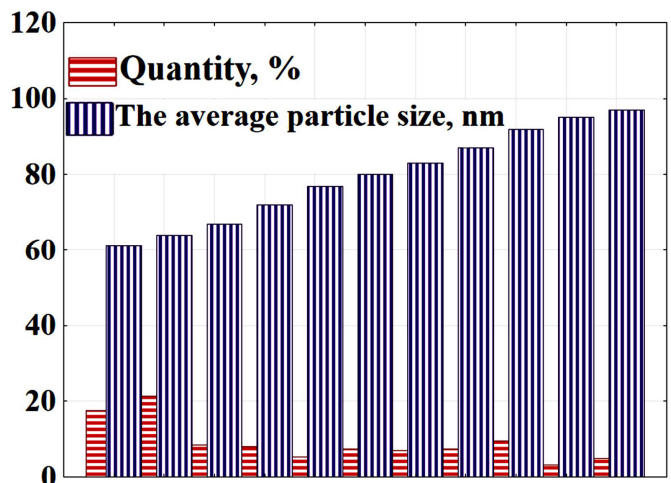

a)

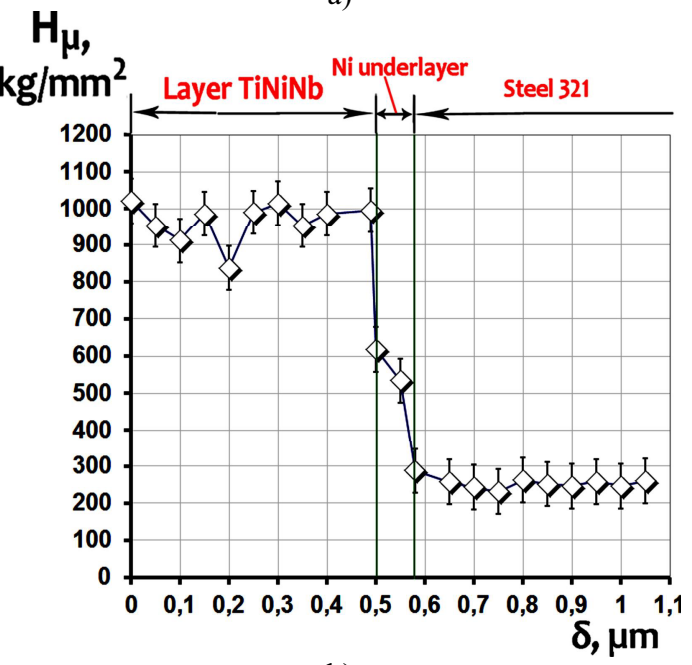

b)

Figure 4. Quantitative distribution of the grain size and their percentage in the TiNiNb coating - a); changing of microhardness in the TiNiNb layer thickness - b).

$\mathrm{X}$-ray analysis results have shown that at room temperature the initial phase state of TiNiNb layer, after high-speed gas-flame spraying of mechanically activated powder in protective argon environment is: austenitic B2 phases with cubic lattice, martensite B19' phases with monoclinic lattice, phases of $\mathrm{Nb}$ solid solution with cubic lattice, phases $\mathrm{Ti}_{2} \mathrm{Ni}$ with cubic lattice; we also detected a small amount of titanium oxide (TiO) with cubic lattice, less than $2 \%$ (Figure 5 ).

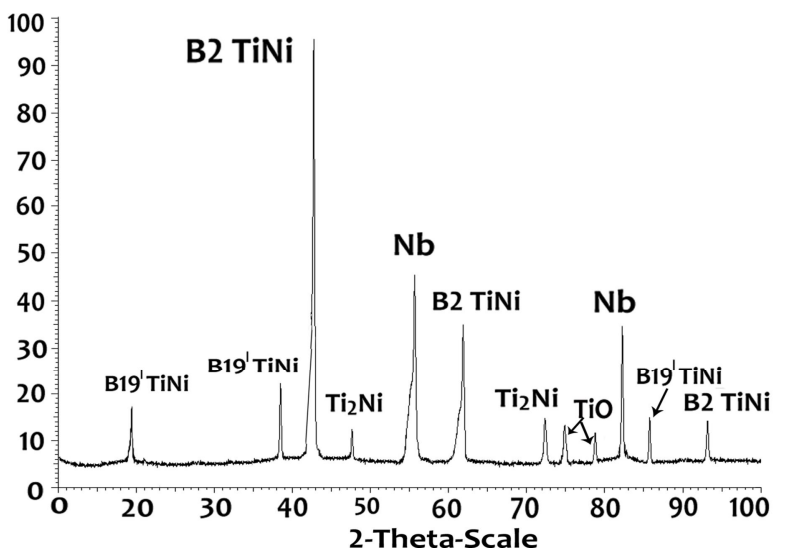

Figure 5. X-ray analysis of the TiNiNb alloy, after high-speed gas-flame spraying with argon areal protection 


\section{MATEC Web of Conferences}

As we can see from X-ray analysis (Figure 5), the TiNiNb layer at room temperature is in the austenitic state. The second main phase, which is in a TiNiNb layer in large numbers is a solid solution based on $\mathrm{Nb}$ with a body-centered cubic lattice. The amount of this phase highly depends on the concentration of $\mathrm{Nb}$ in the layer and increases sharply with increasing concentration of $\mathrm{Nb}$. On the X-ray pattern we observe reflections corresponding to the martensitic phase B19' with monoclinic lattice and intermetallic phase on the basis of $\mathrm{Ti}_{2} \mathrm{Ni}$ with face-centered cubic lattice (Table 2).

Table 2. The parameters of the crystal lattices of phases within the TiNiNb layer

\begin{tabular}{|c|c|c|c|c|c|}
\hline Phase & $\mathbf{a}, \mathbf{n m}$ & $\mathbf{V}_{\mathbf{a}} \mathbf{1 0}^{\mathbf{3}}$ & $\mathbf{b , \mathbf { n m }}$ & $\mathbf{c , n m}$ & $\begin{array}{c}\boldsymbol{\beta}, \\
\text { degree }\end{array}$ \\
\hline $\mathrm{B} 2$ (cubic) & 0,3012 & 27,33 & - & - & 90,00 \\
\hline $\mathrm{Nb}$ (cubic) & 0,3295 & 34,81 & - & - & 109,45 \\
\hline $\begin{array}{c}\mathrm{B} 19^{\prime} \\
\text { (monoclinic) }\end{array}$ & 0,2889 & 51,99 & 0,4376 & 0,4112 & 96,8 \\
\hline $\mathrm{Ti}_{2} \mathrm{Ni}$ (cubic) & 1,1234 & 1417,76 & - & - & 60,00 \\
\hline $\mathrm{TiO}$ (cubic) & 0,407 & 67,42 & - & - & 60,00 \\
\hline
\end{tabular}

For the evaluation of exploitation properties of $\mathrm{TiNiNb}$ coating we made test of surface layers for dry friction wear of the coated sample against the hard rotating disk on 2070 CMT-1 testing machine with the disk rotational speed $\mathrm{v}=0,5 \div 2 \mathrm{~m} / \mathrm{s}$ and the pressure $\mathrm{P}=2 \div 12 \mathrm{MPa}$, while recording temperature in the contact zone. Evaluation of wear rate was made on the basis of experimental data using the application package Statistica v10.0 in the medium SPSS (Figure 6).

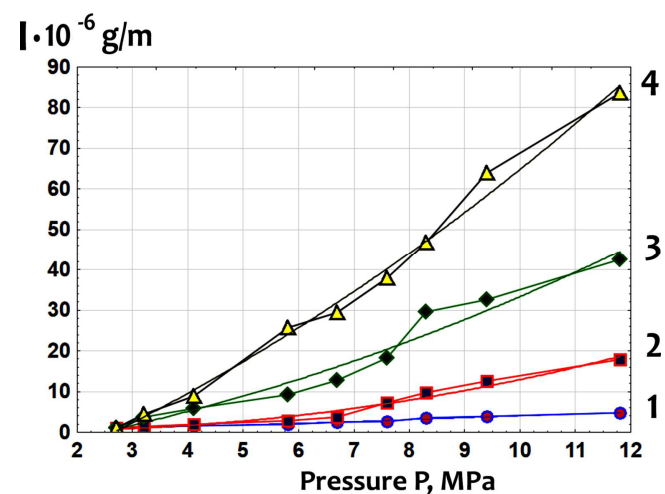

a)

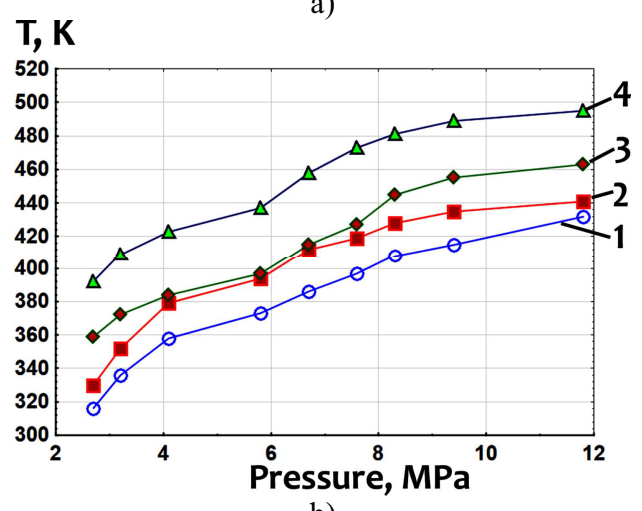

b)

Figure 6. The dependence of the wear rate I on the disk pressure $\mathrm{P}$ (TiNiNb layer obtained by $\mathrm{HVOF}$ in protective environment), (temperature T: $317,3 \div 432,8 \mathrm{~K}-1 ; 331,4 \div$ $441,3 \mathrm{~K}-2 ; 360,7 \div 460,5 \mathrm{~K}-3 ; 393,7 \div 495,7 \mathrm{~K}-4)$-a); dependence of the temperature $\mathrm{T}$ in the friction zone on the disc pressure $\mathrm{P}-\mathrm{b}$ ); disk sliding speed $0.5 \mathrm{~m} / \mathrm{s}-1 ; 1 \mathrm{~m} / \mathrm{s}-2 ; 1.5 \mathrm{~m} /$ $-3 ; 2 \mathrm{~m} /-4$

As a result of the experiments we can see growth in the wear rate at increasing sliding speed and pressure of the disc. The difference in wear rate for the sliding speed of 1 $\mathrm{m} / \mathrm{s}$ and disc pressure less than $7 \mathrm{MPa}$ is small (Figure 6, curve 1 and 2) and wear kinetics is similar change in wear rate over time at low sliding speeds and disk pressures. High values of pressure and disk sliding speed lead to imbalance of friction process in the first period of time 5-15 minutes and high wears (Fig.6, curve 3 and 4). The disc sliding speed has the main effect on the wear rate. When the disk sliding speed is in the range of $1-1.5$ $\mathrm{m} / \mathrm{s}$, the process of sustainable wear is broken. Fig.5a shows that there is no clear partition between the running-in period, the stable and unstable friction.

The dependence of the wear rate I on disk pressure P, sliding at different speeds, is described by equations (47):

- sliding speed $V=0,5 \mathrm{~m} / \mathrm{s}: \mathrm{I}=-0,059+0,353 \cdot \mathrm{P}$

$+0,006 \cdot \mathrm{P}^{2}$

- sliding speed $\mathrm{V}=1 \mathrm{~m} / \mathrm{s}: \mathrm{I}=0,71-0,4 \cdot \mathrm{P}+$

$0,163 \cdot \mathrm{P}^{2}$

- sliding speed $\mathrm{V}=1,5 \mathrm{~m} / \mathrm{s}: \mathrm{I}=-6,05+2,03 \cdot \mathrm{P}+$

$0,192 \cdot \mathrm{P}^{2}$

- sliding speed $\mathrm{V}=2 \mathrm{~m} / \mathrm{s}: \mathrm{I}=-15,85+5,21 \cdot \mathrm{P}+$

$0,286 \cdot \mathrm{P}^{2}$

The temperature in the friction zone "disk - sample" has a significant effect (Figure 6b). The temperature rises in the friction zone with increasing pressure and sliding disk speed (Figure 6b, the curve 1-4). For the surfacemodified TiNiNb layer, the temperature increase has no significant effect on the change in the phase composition and structure. Temperature increase in friction has no effect on the mechanical and functional properties as the temperatures of martensitic transformation are in a negative temperature zone.

As a result of the tests, wear resistance of steel 321, after surface modification with SME TiNiNb alloy, increased by $1,5 \div 2$ times. Increased wear resistance is due to the nanostructured state of $\mathrm{TiNiNb}$ (grain size is 60-97 nm).

\section{Conclusion}

Based on the analysis of the experimental data we defined the optimal technological conditions of surface modification of steel 321 with TiNiNb alloy using highspeed gas-flame spraying in a protective environment. The resulting layers have the structure of B2 phase with cubic lattice, martensite B19' phase with monoclinic lattice, solid solution $\mathrm{Nb}$-based phase with cubic lattice, $\mathrm{Ti}_{2} \mathrm{Ni}$ phase with cubic lattice, as well as small amount of titanium oxide (TiO). The intermediate nickel sub-layer and preliminary processing steps of surface preparation and mechanical activation provide a solid grip on the 
border "Steel - TiNiNb". We identified the controlling parameters of processing which monitor the material structural state at formation stage of surface-modified layer. The test of steel 321 with surface-modified TiNiNb layer in conditions of dry friction, in which there is a significant increase in temperature, has confirmed the effect of wear resistance increase to 1.5-2 times, due to the state of nanostructured layer.

The work was performed as part of the Russian Science Foundation grant (agreement № 15-19-00202 - 2015).

\section{References}

1. Khachin V.N., Pushin V.G., Kondratyev V.V. Nikelid titanium. Structure and Properties. M .: Nauka 302 (1992)

2. Schryvers Dominique, van Aert Sandra. Highresolution visualization techniques: structural aspects Disorder and strain-induced complexity in functional materials. Kakeshita T. [edit.]; et al. [edit.] (2012)

3. Wang Xiebin, Kustov S., Li Kai, Schryvers Dominique, Verlinden Brt, Jan Van Humbeeck. Effect of nanoprecipitates on the transformation behavior and functional properties of a Ti50.8at.\%Ni alloy with micron-sized grains. Acta Materialia, 224-233 (2015)

4. Wei Liu, Qing Xu, Fushun Liu. Effect of $\mathrm{Zr}$ element addition on the mechanical behavior of Ti48.5-xNi49.5Nb2 alloy. Procedia Engineering 27 (2012)

5. Dominique Schryvers, Hui Shi, Gerardo $T$. Martinez, Sandra Van Aert, Jan Frenzel, Jan Van Humbeeck. Nano- and Microcrystal Investigations of Precipitates, Interfaces and Strain Fields in $\mathrm{Ni}-\mathrm{Ti}-\mathrm{Nb}$ by Various TEM Techniques. Materials Science Forum, 65-71, 738-739 (2013)

6. Horikawa H., Suzuki Y., Horie A. et. al. Application of $\mathrm{Ni}-\mathrm{Ti}-\mathrm{Nb}$ shape memory alloy pipe couplings. Proc. Int. Conf. ICOMAT-92, Monterey, 1271-1276 (1993)

7. Udovenko B.A., Potapov P.L., Prokoshkin S.D. et al. Study of the functional properties of the alloy Ti-45\% $\mathrm{Ni}-10 \% \mathrm{Nb}$ with wide hysteresis of martensitic transformation. MITOM 9, 19-22 (2000)

8. P.O. Rusinov, Zh.M. Blednova. Formation of Nanostructure Surface Layers from Materials with Shape Memory Effect TiNiCu in Conditions. Materials Science Forum 738-739, 512-517 (2013)

9. Zh.M. Blednova, P.O. Rusinov, M.A. Stepanenko. Superficial Modifying by Materials with SME in Engineering Appendices. Materials Science Forum 738-739, 595-600, (2013)

10. Zh.M. Blednova, P.O. Rusinov, M.A. Stepanenko. Influence of Superficial Modification of Steels by Materials with SME on Wear-fatigue Characteristics at Frictional-cyclic Loading. Advanced Materials Research 915-916, 509-514 (2014) 
